\title{
Improving outcomes for transplantation in failing Fontan - what is the next target?
}

Barbara Cardoso, MD, ${ }^{a}$ Andras Kelecsenyi, MD, ${ }^{\mathrm{b}}$ Jonathan Smith, MB ChB, MRCP (UK), FRCA, ${ }^{\mathrm{b}, \mathrm{c}}$ Katrijn Jansen, MD, ${ }^{\mathrm{a}, \mathrm{c}}$ Fabrizio De Rita, MD, ${ }^{\mathrm{a}, \mathrm{c}, \mathrm{d}}$ Mohamed Samy Nassar, MD, FRCS, ${ }^{\mathrm{a}, \mathrm{c}, \mathrm{d}, \mathrm{e}}$ and Louise Coats, MBBS, $\mathrm{PhD}^{\mathrm{a}, \mathrm{c}}$

\section{ABSTRACT}

Objective: To identify the key contributors to postoperative mortality in patients undergoing orthotopic heart transplantation (OHT) for late Fontan failure.

Methods: This retrospective review of failing Fontan patients who underwent OHT in our tertiary care center between 2007 and 2019 included adult patients with congenital heart disease and single ventricle physiology who were palliated with a Fontan circulation for $>_{1}$ year. We excluded patients undergoing combined heart-liver transplantation.

Results: The study cohort comprised 31 patients, including 18 males (58.1\%), with a mean weight of $58.4 \mathrm{~kg}$, median age at Fontan of 6.9 years (interquartile range $[\mathrm{IQR}], 2-38$ years), and a median age at OHT of 27.1 years (IQR, 16.7-53.3). Almost all $(93.5 \%)$ of the patients were in New York Heart Association class III-IV, and the majority $(74.2 \%)$ were in Interagency Registry for Mechanically Assisted Circulatory Support class 3 . Overall survival at 30 days, 1 year, and 5 years after OHT was $81 \%, 71 \%$, and $67 \%$, respectively. Major intraoperative bleeding was associated with increased mortality after OHT (odds ratio, 30; 95\% confidence interval, 2.8-322; $P=.002$ ). Neither preoperative systemic ventricular function nor the development of primary graft dysfunction (PGD) was significantly associated with postoperative death. Nevertheless, PGD determined significant morbidity of this population.

Conclusions: In our cohort, major intraoperative bleeding was the key factor associated with mortality after OHT for late Fontan failure. Novel strategies for the prevention and management of postoperative bleeding will improve outcomes in this group of patients. (JTCVS Open 2021;8:565-73)

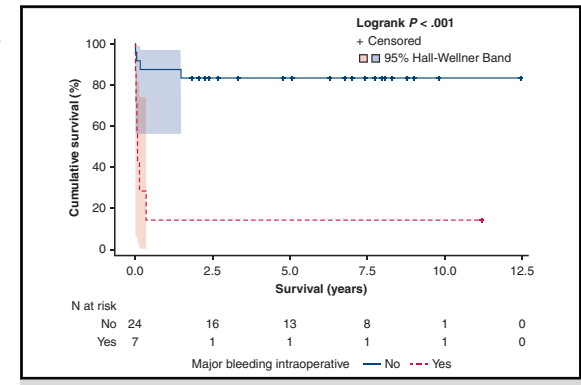

Kaplan-Meier survival curve according to major intraoperative bleeding (time in years).

CENTRAL MESSAGE

Major intraoperative hemorrhage was the key factor associated with post-heart transplantation mortality in an adult failing Fontan population. This was reflected in a 30-day mortality rate of $57 \%$.

\section{PERSPECTIVE}

Heart transplantation for patients with failing Fontan circulation is a high-risk procedure. Major intraoperative hemorrhage was the key factor associated with post-transplantation mortality in our population. Novel strategies to improve the outcomes of this growing patient population are needed and should target the prevention and management of this complication.

See Commentaries on pages 574 and 576.
The Fontan procedure is the final stage in a series of palliative procedures that make it possible to extend the survival of children with univentricular circulation into adulthood. ${ }^{1}$

\footnotetext{
From the ${ }^{a}$ Adult Congenital and Paediatric Heart Unit, ${ }^{\mathrm{b}}$ Department of Anaesthesia, and ${ }^{\mathrm{d}}$ Department of Cardiothoracic Surgery, Freeman Hospital, Newcastle upon Tyne NHS Foundation Trust, Newcastle upon Tyne, United Kingdom; ${ }^{c}$ Congenital Heart Disease Research Group, Population Health Sciences Institute, Newcastle University, Newcastle upon Tyne, United Kingdom; and ${ }^{\mathrm{e}}$ Department of Cardiothoracic Surgery, Alexandria University, Alexandria, Egypt.

The Children's Heart Unit Fund supports the salary of a Fontan specialist nurse who provides clinical care for this patient group. Funding for this work was provided by the Madeleine Steel Charitable Trust.
}

Nonetheless, over time, a significant proportion of Fontan recipients will ultimately develop circulatory failure. The estimated rate of Fontan failure is $7 \%$ by age 20 years

Received for publication Feb 24, 2021; accepted for publication Aug 6, 2021 available ahead of print Sept 7, 2021.

Address for reprints: Barbara Cardoso, MD, Paediatric Heart Unit, Freeman Hospital, Freeman Rd, High Heaton, Newcastle upon Tyne NE7 7DN, United Kingdom (E-mail: barbarapcardoso@ hotmail.com).

2666-2736

Crown Copyright (C) 2021 Published by Elsevier Inc. on behalf of The American Association for Thoracic Surgery. This is an open access article under the CC BY-NCND license (http://creativecommons.org/licenses/by-nc-nd/4.0/).

https://doi.org/10.1016/j.xjon.2021.08.006 


$\begin{array}{ll}\text { Abbreviations and Acronyms } \\ \text { CHD } & =\text { congenital heart disease } \\ \text { CPB } & =\text { cardiopulmonary bypass } \\ \text { ECMO } & =\text { extracorporeal membrane oxygenation } \\ \text { EF } & =\text { ejection fraction } \\ \text { ICU } & =\text { intensive care unit } \\ \text { IVF } & =\text { impaired ventricular function } \\ \text { LV } & =\text { left ventricular } \\ \text { MELD-XI } & =\text { model for end-stage liver disease score } \\ & \text { excluding the international normalized } \\ & \text { ratio } \\ \text { OHT } & =\text { orthotopic heart transplantation } \\ \text { PGD } & =\text { primary graft dysfunction } \\ \text { PVF } & =\text { Preserved ventricular function } \\ \text { RV } & =\text { right ventricular } \\ & \end{array}$

Video clip is available online.

and increases by $>5$-fold to $38 \%$ by age 40 years. $^{2}$ Thus, increasing numbers of end-stage failing Fontan patients present for cardiac transplantation as they age. ${ }^{3}$

Heart transplantation is a high-risk procedure for failing Fontan patients compared with patients with other congenital heart diseases (CHDs). ${ }^{4-6}$ However, the composition of patient populations and different clinical thresholds for transplantation can influence the identification of risk factors when single-center cohorts are interrogated, and contradictory findings have been reported. ${ }^{7}$

The aim of this study was to describe the contemporary perioperative management of adult patients with late failing Fontan undergoing heart transplantation in our tertiary care center and to identify key contributors to their postoperative mortality.

\section{METHODS \\ Study Design and Patient Selection}

Thus is a single-center retrospective cohort study of late failing Fontan patients who underwent orthotopic heart transplantation (OHT) at our tertiary care center between January 2007 and June 2019. This timeframe was selected for convenience, since electronic patient records were introduced in our Trust in 2007. Furthermore, it represents a contemporary cohort and reflects these patients' current management in our center. The patient population described in this article overlaps with the cohort described by Murtuza and colleagues. ${ }^{8}$

We included adult patients (age $>16$ years) with CHD and single ventricle physiology palliated with a Fontan circulation for $>1$ year. We excluded patients in other stages of the single ventricle palliation and those undergoing combined heart-liver transplantation. Data were collected from the patients' electronic records, case notes, and anesthetic charts.

This study was reviewed and a waiver of requirement for approval by a National Health Service Research Ethics Committee was confirmed by the chair of the Northeast Tyne and Wear South Research Ethics Committee.
Requirement for the patients' written consent for publication of the study data was waived. The Caldicott principles of patient information and confidentiality were respected (Caldicott application 6916; December 12, 2018).

\section{Baseline, Management, and Outcome Variables}

Recorded patient baseline characteristics included age, sex, weight, cardiac diagnosis, preoperative systemic ventricular systolic function, previous cardiac surgeries, comorbidities, and pretransplantation clinical status. Management was divided into preoperative, intraoperative, and postoperative stages.

Preoperative cardiac function data were collected from the last echocardiographic report before transplantation. Ventricular systolic function was classified as preserved (ejection fraction $[\mathrm{EF}]>55 \%$ ), mildly impaired (EF $45 \%-54 \%$ ), moderately impaired (EF $30 \%-44 \%$ ) or severely impaired (EF $<30 \%$ ), according to the 2005 European Society of Cardiology/American Society of Echocardiography guidelines. ${ }^{9}$

Patients with preserved or mildly impaired function were included in the preserved ventricular function (PVF) group, and those with moderate to severe systolic impairment were included in the impaired ventricular function (IVF) group. Right ventricular (RV) function was assessed according to tricuspid annular plane systolic excursion and RV fractional area change and classified as severely impaired at a tricuspid annular plane systolic excursion $<1 \mathrm{~cm}$ and an RV fractional area change $\leq 17 \%$. ${ }^{9}$ Preoperative hemodynamic data were collected from the report of the patient's last cardiac catheterization before transplantation.

Major outcomes included survival (30 days, 6 months, 1 year, and 5 years), development of primary graft dysfunction (PGD), and occurrence of major intraoperative bleeding. PGD was diagnosed within 24 hours of cardiac transplantation, whenever a discernible etiology could not be found. PGD was divided into left ventricular (LV) PGD and RVPGD. Severe LV-PGD was defined as dependence on LV or biventricular mechanical support (extracorporeal membrane oxygenation [ECMO], LV assist device, biventricular assist device, or percutaneous LV assist device) and excluded a requirement for an intra-aortic balloon pump. RV-PGD was defined by any of the following criteria: right atrial pressure $>15 \mathrm{~mm} \mathrm{Hg}$, pulmonary capillary wedge pressure $<15 \mathrm{~mm} \mathrm{Hg}$, cardiac index $<2.0 \mathrm{~L} / \mathrm{min} / \mathrm{m}^{2}$, transpulmonary gradient $<15 \mathrm{~mm} \mathrm{Hg}$, and/or pulmonary artery systolic pressure $<50 \mathrm{~mm} \mathrm{Hg}$ or the need for an RV assist device. $^{10}$

In this work, we have used the universal definition for perioperative bleeding in adult cardiac surgery proposed by Dyke and colleagues. ${ }^{11}$ The authors divide perioperative bleeding into 4 categories, from 0 (insignificant) to 4 (massive). We have defined patients with major hemorrhagic events as those meeting the criteria for class 3 (severe) or class 4 (massive) bleeding. Criteria for severe bleeding included (1) delayed sternal closure; (2) chest reexploration, and (3) administration of 5 to 10 units of packed red blood cells or fresh frozen plasma. Criteria for massive bleeding included the administration of $>10$ units of packed red blood cells or fresh frozen plasma. According to Dyke and colleagues, ${ }^{11}$ the presence of the worst single predefined attribute is sufficient to place a patient in a particular bleeding class; the presence of all attributes within a class is not necessary.

The secondary outcomes were post-OHT complications, duration of mechanical ventilation, and intensive care unit (ICU) length of stay. Furthermore, we compared these outcomes among the subgroups of patients who developed PGD and those who developed major intraoperative bleeding.

Complications were subdivided into reoperation at $<48$ hours after index surgery for mediastinal exploration, acute kidney failure, neurologic complications, sepsis, bowel resection, and limb amputation. Acute kidney failure was defined as an abrupt loss of renal function developing within 7 days of surgery and necessitating renal replacement therapy. Neurologic complications included ischemic stroke and intracranial hemorrhage, defined as a new acute neurologic deficit of any duration, associated with imaging findings corresponding anatomically to the clinical deficit. Sepsis was defined as a clinical infection treated with antimicrobial agents in a 
nonprophylactic dosage, with the presence of a positive culture from the infected site or organ unless strong clinical evidence indicated the need for treatment despite negative cultures.

\section{Statistical Analysis}

The distribution of data was assessed using the Shapiro-Wilk test. Continuous variables were reported as mean \pm standard deviation if normally distributed (weight, body surface area, time from Fontan, resting peripheral oxygen saturation, main pulmonary artery pressure, systemic ventricular end-diastolic pressure, preoperative platelet count, model for end-stage liver disease score excluding the international normalized ratio [MELD-XI] score, estimated glomerular filtration rate, donor age, and donor-recipient weight ratio) and as median and interquartile range (IQR)/range if non-normally distributed. Categorical data were expressed as absolute number and percentage. Univariate analysis was performed using the $\chi^{2}$ or Fisher exact test for categorical variables and the independent-samples $t$ test or Mann-Whitney test for continuous variables. Kaplan-Meier analysis was used for survival, with the log-rank test used to determine significant differences. In all analyses, a $P$ value $<.05$ was considered statistically significant. Statistical analyses were performed using SPSS version 20.0 (IBM, Armonk, NY).

\section{RESULTS}

\section{Baseline Characteristics and Pretransplantation Management}

The study cohort comprised 31 patients, including $58.1 \%$ males, with a median age of 27.1 years (IQR, 16.753.3 years) and a mean weight of $58.4 \mathrm{~kg}$. All patients had pre-Fontan univentricular circulations, with a systemic left ventricle in $71 \%$ of cases. The patients' median age at Fontan completion was 6.9 years (IQR, 2-38 years). Diagnoses according to type of pre-Fontan circulation are detailed in Table 1.

At the time of transplantation, 29 patients $(93.5 \%)$ were in New York Heart Association NYHA class III-IV with 23 (74.2\%) in Interagency Registry for Mechanically Assisted Circulatory Support class $3 .{ }^{12}$ Nineteen patients $(61.3 \%)$ had moderate to severe IVF. At the time of the last hemodynamic study before transplantation, their mean pulmonary artery pressure was $15 \pm 5.4 \mathrm{~mm} \mathrm{Hg}$ and median transpulmonary gradient was $4 \mathrm{~mm} \mathrm{Hg}$ (IQR, $2.3 \mathrm{~mm} \mathrm{Hg}$ ). Seven of the 11 patients with aortopulmonary collaterals $(64 \%)$ had undergone preoperative percutaneous embolization.

The patients' mean MELD-XI score ${ }^{13}$ was $12 \pm 3.8$, and their mean estimated glomerular filtration rate was $82.8 \pm 28.3 \mathrm{~mL} / \mathrm{min} / 1.73 \mathrm{~m}^{2}$. Only 1 patient had renal replacement therapy. Seven patients $(22.6 \%)$ had proteinlosing enteropathy. Pretransplantation status and comorbidities are detailed in Table 2.

Most of the patients $(77.4 \%)$ were admitted to hospital and received inotropic support $(74.2 \%)$; they were listed as urgent transplantation candidates. The patients' pretransplantation management is detailed in Table 2.

TABLE 1. Demographics and baseline characteristics according to patient group

\begin{tabular}{|c|c|c|c|c|c|c|}
\hline Characteristic & $\begin{array}{c}\text { Patients with } \\
\text { major intraoperative } \\
\text { bleeding }(\mathbf{N}=7)\end{array}$ & $\begin{array}{l}\text { Other patients } \\
\quad(\mathbf{N}=\mathbf{2 4})\end{array}$ & $P$ value & $\begin{array}{c}\text { Patients with } \\
\text { primary graft } \\
\text { dysfunction }(\mathrm{N}=\mathbf{8})\end{array}$ & $\begin{array}{l}\text { Other patients } \\
\quad(\mathbf{N}=\mathbf{2 3})\end{array}$ & $P$ value \\
\hline Male sex, $n(\%)$ & $4(57.1)$ & $14(58.3)$ & .99 & $6(75)$ & $12(52.2)$ & .41 \\
\hline Weight, $\mathrm{kg}$, mean $\pm \mathrm{SD}$ & $63.8(7.7)$ & $58.7(9.0)$ & .18 & $64(10)$ & $58.4(8.2)$ & .13 \\
\hline $\mathrm{BSA}, \mathrm{m}^{2}$, mean $\pm \mathrm{SD}$ & $1.7(0.1)$ & $1.7(0.1)$ & .23 & $1.7(0.15)$ & $1.6(0.13)$ & .09 \\
\hline Original diagnosis, $\mathrm{n}(\%)$ & & & .28 & & & .11 \\
\hline ARVC post-right ventriculectomy & $1(14.3)$ & $0(0)$ & & $1(12.5)$ & $0(0)$ & \\
\hline HLHS & $0(0)$ & $1(4.2)$ & & $0(0)$ & $1(4.3)$ & \\
\hline DILV + associated lesions & $2(28.6)$ & $6(25)$ & & $2(25)$ & $6(26.1)$ & \\
\hline Tricuspid atresia & $3(42.9)$ & $7(29.2)$ & & $1(12.5)$ & $9(39.1)$ & \\
\hline Unbalanced CAVSD + associated lesions & $1(14.3)$ & $1(4.2)$ & & $2(25)$ & $0(0)$ & \\
\hline DORV + associated lesions & $0(0)$ & $7(29.2)$ & & $2(25)$ & $5(21.7)$ & \\
\hline Pulmonary atresia & $0(0)$ & $2(8.3)$ & & $0(0)$ & $2(8.7)$ & \\
\hline Systemic ventricle, n (\%) & & & & & & .66 \\
\hline Left ventricle & $6(85.7)$ & $16(66.7)$ & .64 & $5(62.5)$ & $17(73.9)$ & \\
\hline Right ventricle & $1(14.4)$ & $8(33.3)$ & & $3(37.5)$ & $6(26.1)$ & \\
\hline Previous thoracotomies, n, median (range) & $1(0-2)$ & $1(0-2)$ & .37 & $0(1)$ & $1(1)$ & .15 \\
\hline Previous sternotomies, $\mathrm{n}$, median (range) & $3(1-4)$ & $2(1-5)$ & .73 & $2.5(1.8)$ & $2(1)$ & .67 \\
\hline Type of Fontan, n (\%) & & & .83 & & & .71 \\
\hline Atriopulmonary & $1(14.3)$ & $3(12.5)$ & .39 & $0(0)$ & $4(17.4)$ & \\
\hline Lateral tunnel & $1(14.3)$ & $8(33.3)$ & & $3(37.5)$ & $6(26.1)$ & \\
\hline Extracardiac & $5(71.4)$ & $13(54.2)$ & & $5(62.5)$ & $13(56.5)$ & \\
\hline Fenestrated Fontan, n (\%) & $2(28.6)$ & $12(52.2)$ & .99 & $6(75)$ & $8(36.4)$ & .10 \\
\hline Time from Fontan to OHT, $y$, mean \pm SD & $14.2(9.97)$ & $19.9(6.43)$ & .08 & $14.5(9.5)$ & $20(6.4)$ & .07 \\
\hline
\end{tabular}

$S D$, Standard deviation; $B S A$, body surface area; $A R V C$, arrhythmogenic right ventricular cardiomyopathy; $H L H S$, hypoplastic left heart syndrome; $D I L V$, double-inlet left ventricle; $C A V S D$, complete atrioventricular septal defect; $D O R V$, double-outlet right ventricle; $O H T$, orthotopic heart transplantation. 


\section{Intraoperative Management}

Patients underwent cardiac transplantation after a median time on the transplantation list of 45 days (IQR, 92 days). The mean donor age was $32 \pm 12.4$ years, median donor weight was $79.6 \mathrm{~kg}$ (IQR, $15 \mathrm{~kg}$ ), and median donorrecipient weight ratio was 1.4 . The majority of donors were male $(77.4 \%)$, and there were $10(32.3 \%)$ sex-mismatched transplantations. The median donor ischemic time was $182 \mathrm{mi}-$ nutes (IQR, 111 minutes), and the median warm ischemic time was 46.5 minutes (IQR, 12.5 minutes).

Anesthesia was maintained with total intravenous anesthesia in $16.1 \%$, sevoflurane in $9.7 \%$, and isoflurane in $71 \%$ of cases. Patients received antibiotic prophylaxis and immunosuppressive therapy based on local institutional guidance. In addition to standard American Society of Anesthesiologists monitoring, bilateral regional brain perfusion was monitored using cerebral oximetry (INVOS; Medtronic, Minneapolis, Minn).

Femoral bypass was instituted in 2 patients due to major bleeding — right atrial tear and ascending aorta injury — during preliminary dissection. In 2 other patients, the femoral vein was electively cannulated because of interrupted inferior vena cava anatomy.
The complexity of the repair required in some patients dictated an early start of cardiopulmonary bypass (CPB) to address any required arterial or venous reconstruction before the graft's arrival in the operating theatre. On completion of vascular reconstruction, the graft was brought to the field, a dose of cardioplegia was given, and an interatrial communication was created to aid left side decompression, should ECMO be required later. The anastomoses were performed in the following order: left atrium, pulmonary artery, aorta, inferior vena cava, and superior vena cava. The pulmonary arterial anastomosis was performed prior to the aortic anastomosis because pulmonary artery interventions are often required in these patients.

$\mathrm{CPB}$ prime contained fresh frozen plasma in 26 patients $(83.9 \%)$, mannitol in $20(64.5 \%)$ and aprotinin in 23 (74.2\%). All patients received heparin $400 \mathrm{IU} / \mathrm{kg}$ before initiation of $\mathrm{CPB}$, and an activated clotting time $>600$ seconds was maintained. Supernormal flows were used aiming for $125 \%$ to $130 \%$ of the calculated normal flow of $2.4 \mathrm{~L} / \mathrm{min} / \mathrm{m}^{2}$. The CPB strategy included maintaining the hematocrit level around $30 \%$. Patients were cooled down to $32^{\circ} \mathrm{C}$, and a pH strategy was used. A warm dose of cardioplegia was administered before removal of the aortic

TABLE 2. Pretransplantation status, comorbidities, and management according to patient group

\begin{tabular}{|c|c|c|c|c|c|c|}
\hline Parameter & $\begin{array}{c}\text { Patients with } \\
\text { major intraoperative } \\
\text { bleeding }(\mathbf{N}=7)\end{array}$ & $\begin{array}{l}\text { Other patients } \\
\quad(\mathrm{N}=\mathbf{2 4})\end{array}$ & $P$ value & $\begin{array}{l}\text { Patients with } \\
\text { primary graft } \\
\text { dysfunction } \\
(\mathbf{N}=\mathbf{8})\end{array}$ & $\begin{array}{l}\text { Other patients } \\
\quad(\mathbf{N}=\mathbf{2 3}) \\
\end{array}$ & $P$ value \\
\hline \multicolumn{7}{|l|}{ Cardiac function } \\
\hline NYHA class III-IV, n (\%) & $7(100)$ & $22(91.6)$ & .62 & $8(100)$ & $21(91.3)$ & .21 \\
\hline Resting $\mathrm{SpO}_{2}(\%)$, mean $\pm \mathrm{SD}$ & $87(9)$ & $89.5(5.4)$ & .09 & $89(8.3)$ & $89(5.6)$ & .99 \\
\hline Systemic ventricular function, $\mathrm{n}(\%)$ & & & .007 & & & .99 \\
\hline Preserved ventricular function & $6(85.7)$ & $6(25)$ & & $3(37.5)$ & $9(39.1)$ & \\
\hline Impaired ventricular function & $1(14.3)$ & $18(75)$ & & $5(62.5)$ & $14(60.9)$ & \\
\hline AV valve regurgitation, $\mathrm{n}(\%)$ & & & .39 & & & .22 \\
\hline Trivial to mild & $5(71.4)$ & $11(45.8)$ & & $6(75)$ & $10(43)$ & \\
\hline Moderate to severe & $2(28.6)$ & $13(54.2)$ & & $2(25)$ & $13(56.5)$ & \\
\hline \multicolumn{7}{|l|}{ Hemodynamic data } \\
\hline MPA pressure, $\mathrm{mm} \mathrm{Hg}$, mean $\pm \mathrm{SD}$ & $17.3(4.3)$ & $14.0(5.5)$ & .21 & $13.9(4.5)$ & $15(5.7)$ & .62 \\
\hline TPG, mm Hg, median (IQR) & $4.0(2.0)$ & $4.0(3.0)$ & .63 & $4(1)$ & $4(3)$ & .43 \\
\hline $\begin{array}{l}\text { Systemic ventricle EDP, } \mathrm{mm} \mathrm{Hg} \text {, } \\
\text { mean } \pm \mathrm{SD}\end{array}$ & $12.5(5.0)$ & $10.4(5.1)$ & .76 & $8.9(3.8)$ & $11.7(5.3)$ & .22 \\
\hline \multicolumn{7}{|l|}{ Liver function } \\
\hline MELD-XI, mean \pm SD & $12.4(3.5)$ & $13.0(3.6)$ & .56 & $11.7(2.1)$ & $13.4(3.9)$ & .30 \\
\hline \multicolumn{7}{|l|}{ Renal function } \\
\hline $\mathrm{eGFR}, \mathrm{mL} / \mathrm{min} / 1.73 \mathrm{~m}^{2}$, mean $\pm \mathrm{SD}$ & $81.4(25.1)$ & $70.1(39.0)$ & .41 & $84.1(43.9)$ & $68.6(33.3)$ & .31 \\
\hline Protein-losing enteropathy, n (\%) & $2(28.6)$ & $5(20.8)$ & .64 & $1(12.5)$ & $6(26.1)$ & .64 \\
\hline Plastic bronchitis, n (\%) & $0(0)$ & $0(0)$ & & $0(0)$ & $0(0)$ & \\
\hline \multicolumn{7}{|l|}{ Pretransplantation management } \\
\hline Inpatient at time of transplantation, $\mathrm{n}(\%)$ & $5(71.4)$ & $19(79.2)$ & .64 & $7(87.5)$ & $17(73.9)$ & .64 \\
\hline Inotropic support, $\mathrm{n}(\%)$ & $5(71.4)$ & $18(75)$ & .99 & $7(87.5)$ & $16(69.6)$ & .64 \\
\hline Time on transplant list, d, median (IQR) & $45(99.0)$ & $47(90.5)$ & .91 & $61.5(70)$ & 45 (127) & .86 \\
\hline
\end{tabular}

Significant $P$ values are in bold type. $N Y H A$, New York Heart Association; $S p O_{2}$, peripheral oxygen saturation; $S D$, Standard deviation; $A V$, atrioventricular; $M P A$, main pulmonary artery; $T P G$, transpulmonary gradient; $I Q R$, interquartile range; $E D P$, end-diastolic pressure; $M E L D-X I$, model for end-stage liver disease score excluding international normalized ratio; $e G F R$, estimated glomerular filtration rate. 
cross-clamp to ensure even rewarming of the donor heart. The median time on CPB was 241 minutes (IQR, 100 minutes). Inotropic support while coming off bypass typically included milrinone, vasopressin, and/or noradrenaline and adrenaline.

Coagulation management was a major aspect of anesthesia. Patients who had been on warfarin received vitamin $\mathrm{K}$ on induction $(35.5 \%)$ or prothrombin complex concentrate $(19.4 \%$; Beriplex P/N; CSL Behring, King of Prussia, $\mathrm{Pa})$. Most patients $(87.1 \%)$ received a continuous infusion of aprotinin, and $29 \%$ received tranexamic acid. Baseline and post-protamine thromboelastography were used to guide transfusion therapy.

\section{Posttransplantation Management and Complications}

Seven patients (22.6\%) required chest reexploration less than 48 hours after their primary surgery due to bleeding; nine patients $(29 \%)$ had delayed chest closure. Nine patients $(29 \%)$ required postoperative veno-arterial ECMO (3 with LV-PGD, 4 with RV-PGD, and 1 with cardiopulmonary resuscitation with cannulation onto ECMO) for a median of 2.4 days (IQR, 1-26 days). Seven patients $(22.6 \%)$ developed a postoperative neurologic complication; of these, 6 had received ECMO. Overall, the median duration of mechanical ventilation was 12 hours (IQR, 28 hours), and the median duration of inotropic support was 8 days (IQR, 7.5 days). The majority of patients $(77.4 \%)$ developed posttransplantation kidney injury necessitating renal replacement therapy for a median of 10 days (IQR, 24 days). Nine patients $(29 \%)$ developed postoperative sepsis. One patient $(3.2 \%)$ required bowel resection due to acute ischemia, and 3 patients $(9.7 \%)$ underwent limb amputation. The median ICU length of stay was 11 days (IQR, 25 days), and the median total hospital length of stay was 60 days (IQR, 72 days).
Compared with the other patients, patients with major intraoperative bleeding and PGD required a longer duration of vasopressor and ECMO support, as well as of mechanical ventilation. They accrued significantly more morbidity in the form of neurologic complications and sepsis and had longer ICU stays (Table 3).

\section{Major Outcomes}

Ten patients $(32.3 \%)$ died after a median follow-up of 30.5 months (IQR, 84.9 months). In-hospital mortality was $29 \%$ (9 patients), at a median of 21 days post-OHT. One patient died at 2 years post-OHT.

In our study cohort, most of the deaths occurred early, with an overall 30 -day survival of $80.6 \%$. Survival of these patients plateaued at 6 months at $71 \%$, with 1 -year and 5-year survival rates of $71 \%$ and $67.2 \%$, respectively (Figure 1). Seven patients $(22.6 \%)$ had a major intraoperative hemorrhage, and $8(25.8 \%)$ developed PGD (4 with LV-PGD and 4 with RV-PGD). Three patients had both of these complications.

\section{Predictors of Mortality}

Major intraoperative bleeding (odds ratio, 30; 95\% confidence interval $[\mathrm{CI}], 2.8-322 ; P=.002$ ) was associated with increased mortality after OHT. This group had a significantly higher mortality compared with their counterparts, with a 30 -day-survival of only $43 \%(P<.001)$ (Figure 2$)$. Conversely, neither the occurrence of PGD $(P=.683)$ (Figure 3) nor preoperative systemic ventricle systolic function $(P=.067)$ (Figure 4$)$ was associated with postoperative mortality in this cohort.

\section{Determinants of Bleeding}

The occurrence of major intraoperative bleeding was significantly higher in patients with preoperative PVF

TABLE 3. Postoperative complications according to patient group

\begin{tabular}{|c|c|c|c|c|c|c|}
\hline Complication & $\begin{array}{c}\text { Patients with } \\
\text { major intraoperative } \\
\text { bleeding }(N=7)\end{array}$ & $\begin{array}{l}\text { Other patients } \\
\quad(\mathbf{N}=\mathbf{2 4})\end{array}$ & $P$ value & $\begin{array}{c}\text { Patients with } \\
\text { primary graft } \\
\text { dysfunction }(\mathrm{N}=\mathbf{8})\end{array}$ & $\begin{array}{l}\text { Other patients } \\
\qquad(\mathbf{N}=\mathbf{2 3})\end{array}$ & $P$ value \\
\hline Duration of vasopressors, $\mathrm{d}$, median (IQR) & $26(28)$ & $2(5)$ & $<.001$ & $26(28)$ & $2(6)$ & .003 \\
\hline Postoperative ECMO, n (\%) & $4(57.1)$ & $5(20.5)$ & .150 & $7(87.5)$ & $2(8.7)$ & $<.001$ \\
\hline Duration of ECMO, d, median (IQR) & $5(19)$ & $\mathbf{0}(\mathbf{0})$ & .014 & $5(14.8)$ & $\mathbf{0}(\mathbf{0})$ & $<.001$ \\
\hline Duration of ventilation, $h$, median (IQR) & $51(40)$ & $5(22.8)$ & .005 & $42.5(80.8)$ & $5(20)$ & .001 \\
\hline $\mathrm{AKF}, \mathrm{n}(\%)$ & $7(100)$ & $17(70.8)$ & .161 & $8(100)$ & $16(69.6)$ & .146 \\
\hline Duration of RRT, d, median (IQR) & $26(49)$ & $8.5(23)$ & .043 & $39.5(120.8)$ & $9(21)$ & .034 \\
\hline Neurologic complications, n (\%) & $4(57.1)$ & 3 (12.5) & .029 & $5(62.5)$ & $2(8.7)$ & .006 \\
\hline Sepsis, n (\%) & 5 (71.4) & 4 (16.7) & .012 & $5(62.5)$ & $4(17.4)$ & .027 \\
\hline Bowel resection, n (\%) & $1(14.3)$ & $0(0)$ & .226 & $0(0)$ & $1(4.3)$ & .99 \\
\hline Limb amputation, $\mathrm{n}(\%)$ & $2(28.6)$ & $1(4.2)$ & .120 & $2(25)$ & $1(4.3)$ & .156 \\
\hline ICU length of stay, d, median (IQR) & $26(49)$ & $5(13)$ & .033 & $29.5(59)$ & $10(15)$ & .030 \\
\hline
\end{tabular}

Significant values are in bold type. $I Q R$, Interquartile range; $E C M O$, extracorporeal membrane oxygenation; $A K F$, acute kidney failure; $R R T$, renal replacement therapy; $I C U$, intensive care unit. 


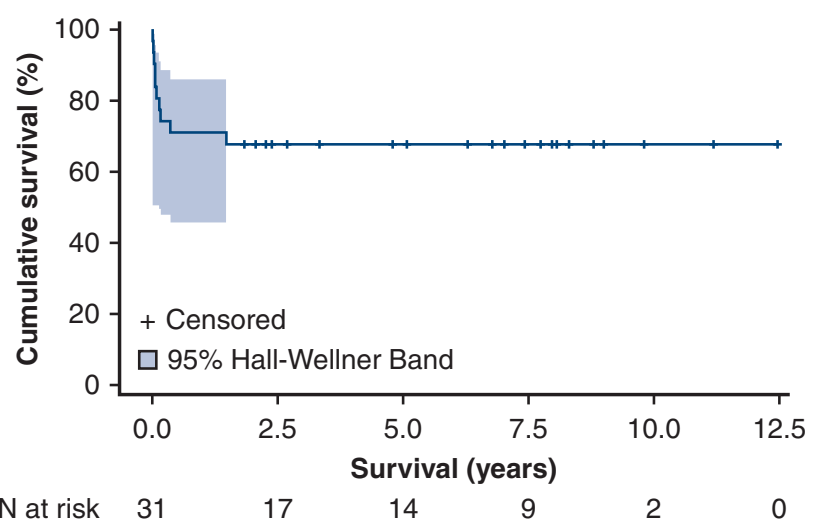

FIGURE 1. Kaplan-Meier survival curve for the overall population of adult failing Fontan patients undergoing heart transplantation (time in years).

compared with those with IVF $(85.7 \%$ vs $14.3 \%$; $P=.007)$.The intraoperative administration of vitamin K (28.6\% vs $37.5 \% ; P=.39)$, Beriplex $(14.3 \%$ vs $20.8 \%$; $P=.99)$, aprotinin $(85.7 \%$ vs $87.5 \% ; P=.99)$, and tranexamic acid $(0 \%$ vs $37.5 \% ; P=.13)$ did not differ significantly between the 2 groups.

Major intraoperative bleeding was significantly associated with longer total surgical duration (median, 12 hours vs 8 hours; $P=.003$ ) and longer CPB time (median, 296 minutes vs 217 minutes; $P=.011$ ).

\section{DISCUSSION}

In our single-center experience of OHT in adults with late Fontan failure, our main finding was the association of major intraoperative bleeding with increased postoperative mortality. Conversely, neither the occurrence of PGD nor the preoperative systemic ventricular function correlated with the increased mortality of these patients. Nevertheless, PGD was associated with significant morbidity. Despite the increased early posttransplantation mortality, the mediumterm survival of these patients was reasonable.

\section{Survival}

Multi-institutional studies have identified the Fontan procedure as a risk factor for early mortality after cardiac transplantation, with a similar long-term survival as that of other CHD patients. ${ }^{14,15}$ Our observed in-hospital mortality of $29 \%$ compares favorably with the $26.3 \%$ reported by Hernandez and colleagues ${ }^{16}$ in a US multi-institutional study spanning the last decade. In our cohort, mortality plateaued at 6 months, with good medium-term survival of $71 \%$ at 1 year and $67 \%$ at 5 years.

These findings are in line with the results of a recently published meta-analysis that included a total of 351 Fontan patients undergoing OHT and showed 1- and 5-year survival rates of $80.3 \%(95 \% \mathrm{CI}, 75.9 \%-84.2 \%)$ and $71.2 \%(95 \%$ CI, $66.3 \%-75.7 \%)$, respectively. ${ }^{17}$

\section{Primary Graft Failure}

Primary graft failure is a known complication after OHT for failing Fontan circulation. ${ }^{18,19}$ It may be attributed to allosensitization in the context of multiple reoperations, prolonged CBP time, elevated pulmonary vascular resistance that is unmasked after transplantation, ${ }^{20}$ and comorbidities, such as renal and liver dysfunction. ${ }^{10}$

Our analysis did not show a significantly increased incidence of primary graft failure $(26 \%)$ in our cohort, which lies at the upper end of that described in literature for nonCHD transplantation $(2.3 \%-28.2 \%) .{ }^{10}$ Postoperatively, this

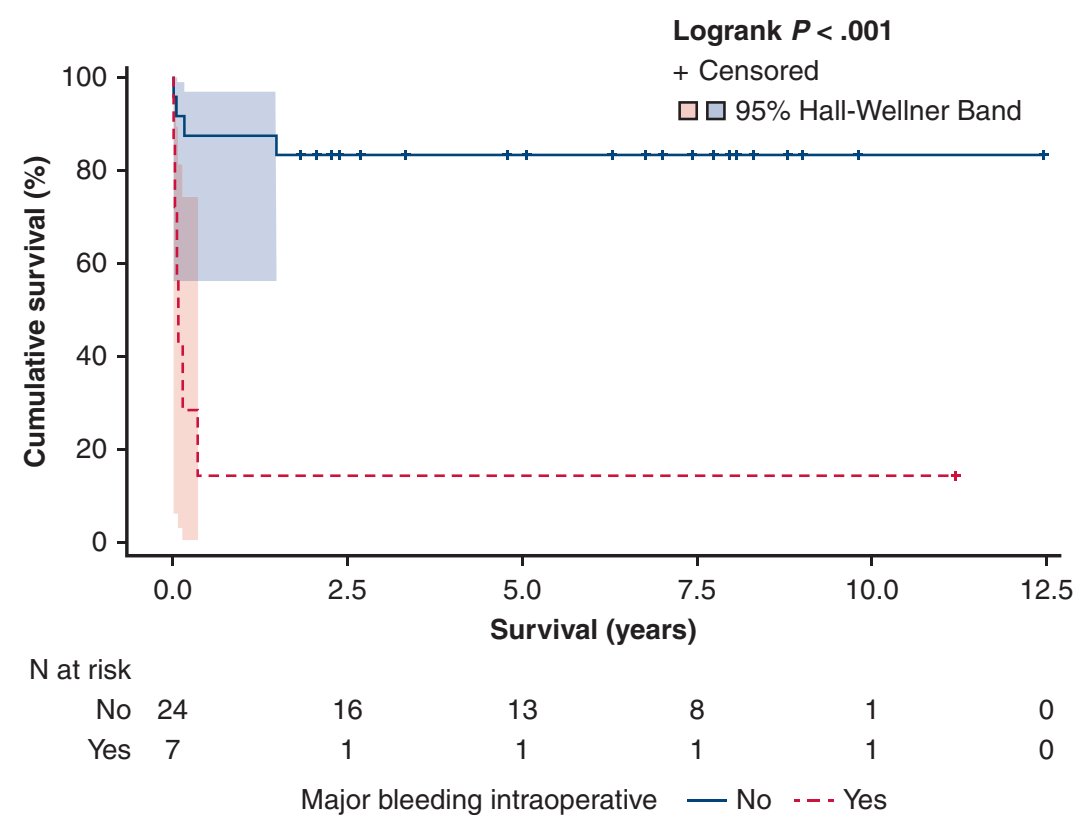

FIGURE 2. Effect of major intraoperative bleeding on survival after heart transplantation in adult failing Fontan patients (time in years). 


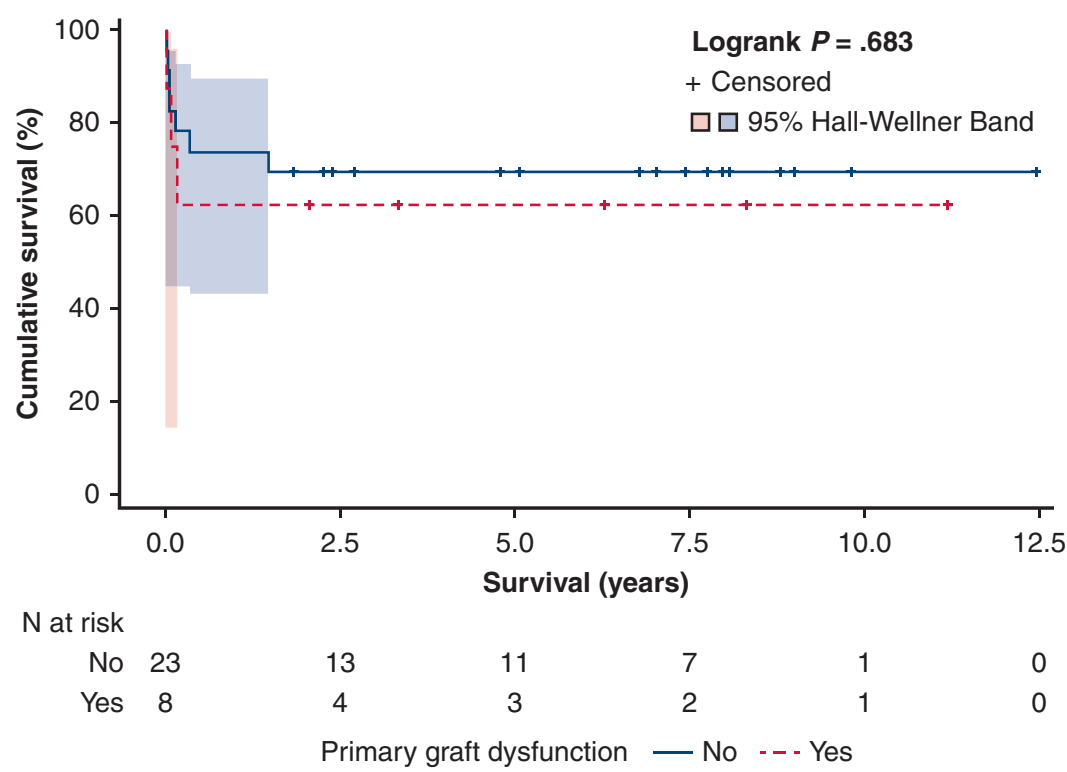

FIGURE 3. Effect of acute graft dysfunction on survival after heart transplantation in adult failing Fontan patients (time in years).

group of patients was successfully supported with ECMO until recovery of cardiac function, and this did not result in increased mortality. Nevertheless, these patients experienced significant postoperative morbidity. Notably, the majority $(86 \%)$ of patients who developed a postoperative neurologic complication had undergone ECMO.

\section{Perioperative Bleeding}

Perioperative bleeding is another well-described complication in this group of patients. Miller and colleagues ${ }^{19}$ reported a $50 \%$ incidence of significant postoperative bleeding in their cohort of failing Fontan patients undergoing OHT. Similarly, Hernandez and colleagues ${ }^{16}$ reported a $>5$-fold higher risk of post-OHT bleeding in Fontan patients compared with non-Fontan patients (odds ratio, 5.32; $P=.015$ ).

The etiology of bleeding in Fontan patients is multifactorial and includes thoracic collateralization, previous operations involving extensive adhesiolysis and long bypass times, preexisting liver disease and coagulopathy, the use of pretransplantation thromboprophylaxis, vasoplegia, ${ }^{21}$ and endothelial dysfunction. ${ }^{22}$

Our key finding was the association of major intraoperative bleeding with increased postoperative mortality. In fact, the group with major intraoperative hemorrhage had a 30-day mortality rate of 57\% (Figure 5). All these patients required early chest exploration for hemostasis. In our

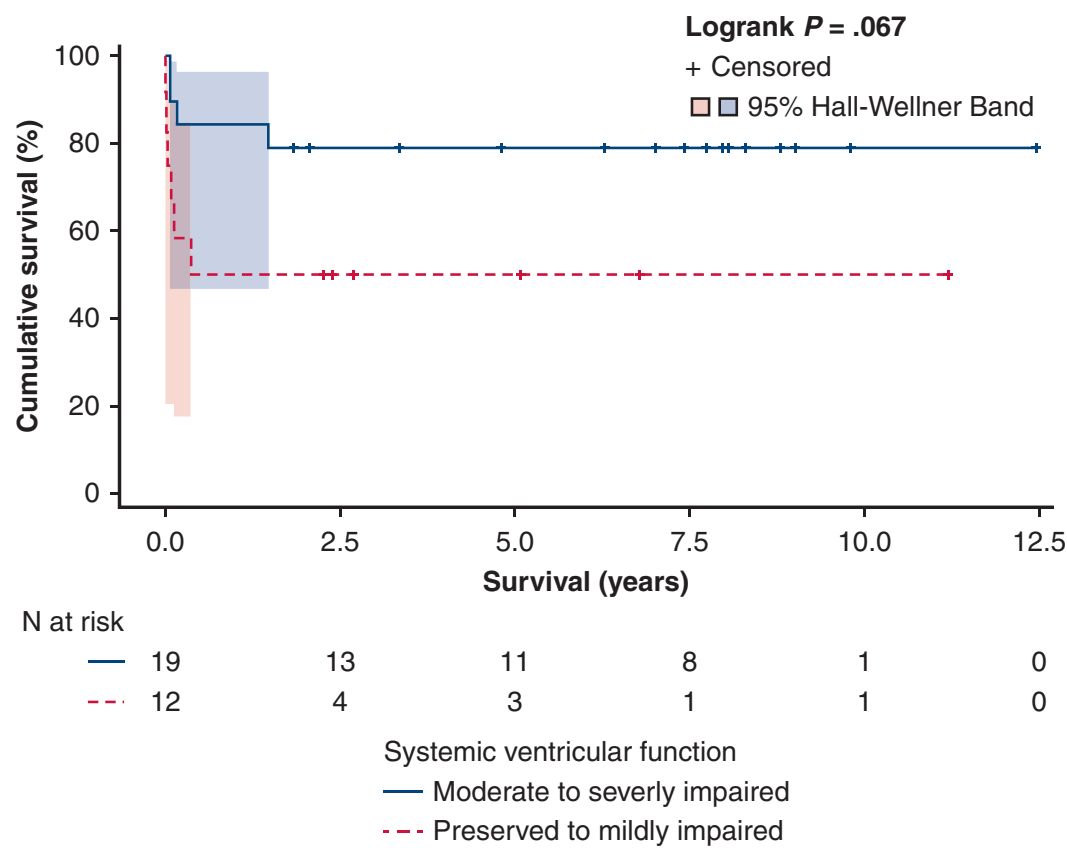

FIGURE 4. Effect of acute graft dysfunction on survival after heart transplantation in adult failing Fontan patients (time in years). 
cohort, this complication resulted from injury to cardiovascular structures during dissection $(n=2)$, bleeding from the anastomotic site $(\mathrm{n}=1)$, and, in the remaining 4 patients, extensive adhesiolysis combined with coagulopathy secondary to a long bypass run. Not unexpectedly, bleeding was associated with longer total duration of surgery and time on CPB. Interestingly, preoperative PVF was associated with the occurrence of major intraoperative bleeding. However, preoperative collateral embolization did not significantly affect the occurrence of bleeding in our cohort, and neither did the use of intraoperative vitamin K, Beriplex, aprotinin, or tranexamic acid. Unfortunately, our study was insufficiently powered to detect statistically significant differences among these interventions.

\section{PVF}

Controversy exists about the value of systemic ventricular function as a predictor of post-transplantation mortality in failing Fontan patients. ${ }^{23}$ Several reports (including one from our group) have identified PVF as a risk factor for post-transplantation mortality and as a surrogate for failing Fontan physiology and increased pulmonary vascular resistance. ${ }^{8}$ Interestingly, in our cohort, pretransplantation ventricular function did not significantly impact post-transplantation mortality.
In a recent study, Miller and colleagues ${ }^{19}$ found that in the current era, patients with PVF had the most significant increase in post-transplantation survival, and that this could be attributable in part to modifications of risk factors specific to this population. We hypothesize that this also could have occurred in our cohort, and that our results potentially reflect the implementation of specific management strategies including preoperative cross-sectional imaging to plan for chest reentry and anatomic reconstruction, volume load reduction with AP collateral embolization, and a higher goal donor-recipient weight ratio. Furthermore, we targeted supranormal CPB flows to account for collateral flow, routinely used milrinone and inhaled nitric oxide, and aggressively monitored for and treated post-OHT vasoplegia.

That being said, however, the relationship of preoperative PVF and post-transplantation risk is complex, remains to be fully elucidated, and needs further study.

\section{Limitations}

This study has limitations that are inherent to its singlecenter and retrospective design. The sample size is small, and the overlap of outcomes precludes drawing strong conclusions despite the use of standard statistical methods and
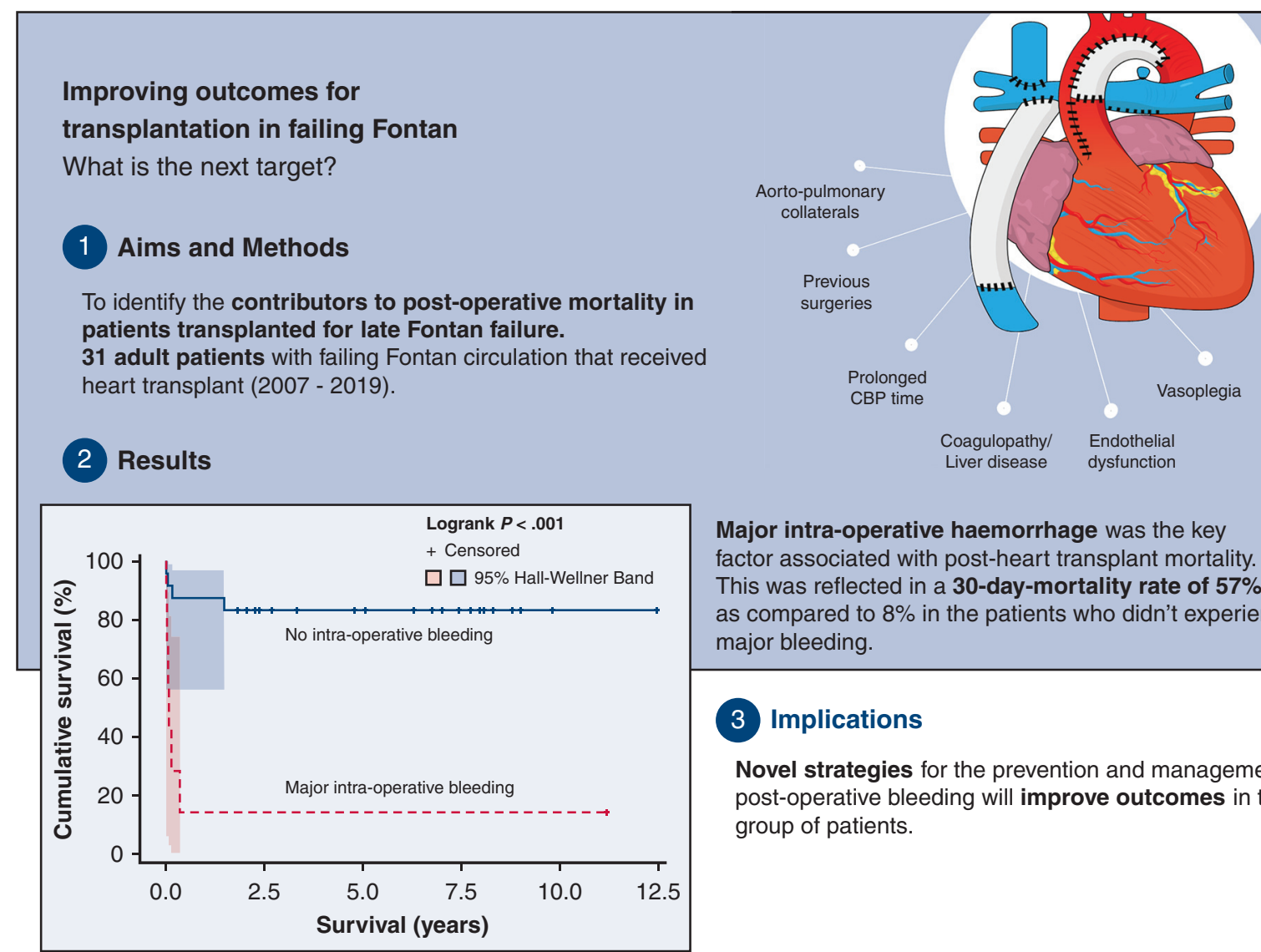

Major intra-operative haemorrhage was the key factor associated with post-heart transplant mortality. This was reflected in a $\mathbf{3 0}$-day-mortality rate of $\mathbf{5 7 \%}$ as compared to $8 \%$ in the patients who didn't experience major bleeding.

\section{(3) Implications}

Novel strategies for the prevention and management of post-operative bleeding will improve outcomes in this group of patients.

FIGURE 5. Major intraoperative hemorrhage was the key factor associated with post-heart transplantation mortality in an adult failing Fontan population. This was reflected in a 30 -day mortality rate of $57 \%$. 


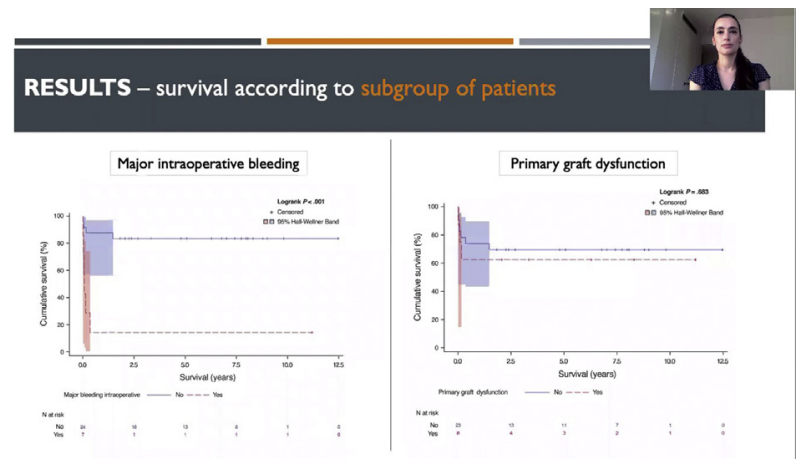

VIDEO 1. Improving outcomes for transplantation in failing Fontanwhat is the next target? Video available at: https://www.jtcvs.org/article/ S2666-2736(21)00233-3/fulltext.

$P$ values. Any inferences drawn from the present data should be validated in future larger, multicenter studies.

\section{CONCLUSIONS}

Favorable outcomes may be achieved in adults with late failing Fontan circulation undergoing OHT. Early postoperative mortality remains concerning and is associated with the occurrence of major intraoperative bleeding. Although not associated with an increased risk of mortality, PGD was correlated with significant morbidity in this population. Contrary to previously published results, pretransplantation systemic ventricular function had no impact on post-transplantation survival in our cohort. We hypothesize that this may be attributable to the implementation of procedures targeted at reducing risk factors specific to this population. Novel strategies to improve outcomes in this group of patients are needed and should target the prevention and management of postoperative bleeding (Video 1). This should be the focus of future prospective studies.

\section{Conflict of Interest Statement}

The authors reported no conflicts of interest.

The Journal policy requires editors and reviewers to disclose conflicts of interest and to decline handling or reviewing manuscripts for which they may have a conflict of interest. The editors and reviewers of this article have no conflicts of interest.

\section{References}

1. Fontan F, Baudet E. Surgical repair of tricuspid atresia. Thorax. 1971;26:240-8.

2. Dennis M, Zannino D, du Plessis K, Bullock A, Disney PJS, Radford DJ, et al. Clinical outcomes in adolescents and adults after the Fontan procedure. $J$ Am Coll Cardiol. 2018;71:1009-17.

3. Crossland DS, Jansen K, Parry G, Harper A, Perri G, Davidson A, et al. Outcome following heart transplant assessment in adults with congenital heart disease. Heart. 2019;105:1741-7.

4. Deal BJ, Jacobs ML. Management of the failing Fontan circulation. Heart. 2012; 98:1098-104.
5. Backer CL, Russell HM, Pahl E, Mongé MC, Gambetta K, Kindel SJ, et al. Heart transplantation for the failing Fontan. Ann Thorac Surg. 2013;96:1413-9.

6. Lamour JM, Kanter KR, Naftel DC, Chrisant MR, Morrow WR, Clemson BS, et al. The effect of age, diagnosis, and previous surgery in children and adults undergoing heart transplantation for congenital heart disease. J Am Coll Cardiol. 2009;54:160-5.

7. Polyviou S, O'Sullivan J, Hasan A, Coats L. Mortality risk stratification in small patient cohorts: the post-Fontan heart transplantation paradigm. Am J Cardiol. 2018;122:182-3.

8. Murtuza B, Hermuzi A, Crossland DS, Parry G, Lord S, Hudson M, et al. Impact of mode of failure and end-organ dysfunction on the survival of adult Fontan patients undergoing cardiac transplantation. Eur J Cardiothorac Surg. 2017;51:135-41.

9. Lang RM, Bierig M, Devereux RB, Flachskampf FA, Foster E, Pellikka PA, et al. Recommendations for chamber quantification: a report from the American Society of Echocardiography's guidelines and Standards Committee and the Chamber Quantification Writing Group, developed in conjunction with the European Association of Echocardiography, a branch of the European Society of Cardiology. $J$ Am Soc Echocardiogr. 2005;18:1440-63.

10. Kobashigawa J, Zuckermann A, Macdonald P, Leprince P, Esmailian F, Luu M, et al. Report from a consensus conference on primary graft dysfunction after cardiac transplantation. J Heart Lung Transplant. 2014;33:327-40.

11. Dyke C, Aronson S, Dietrich W, Hofmann A, Karkouti K, Levi M, et al. Universal definition of perioperative bleeding in adult cardiac surgery. J Thorac Cardiovasc Surg. 2014;147:1458-63.e1.

12. Kirklin JK, Naftel DC, Stevenson LW, Kormos RL, Pagani FD, Miller MA, et al. INTERMACS database for durable devices for circulatory support: first annual report. J Heart Lung Transplant. 2008;27:1065-72.

13. Assenza GE, Graham DA, Landzberg MJ, Valente AM, Singh MN, Bashir A, et al. MELD-XI score and cardiac mortality or transplantation in patients after Fontan surgery. Heart. 2013;99:491-6.

14. Doumouras BS, Alba AC, Foroutan F, Burchill LJ, Dipchand AI, Ross HJ. Outcomes in adult congenital heart disease patients undergoing heart transplantation: a systematic review and meta-analysis. J Heart Lung Transplant. 2016;35: $1337-47$.

15. Riggs KW, Zafar F, Radzi Y, Yu PJ, Bryant R III, Morales DLS. Adult congenital heart disease: current early expectations after cardiac transplantation. Ann Thorac Surg. 2020;109:480-6.

16. Hernandez GA, Lemor A, Clark D, Blumer V, Burstein D, Byrne R, et al. Heart transplantation and in-hospital outcomes in adult congenital heart disease patients with Fontan: a decade nationwide analysis from 2004 to 2014. J Card Surg. 2020;35:603-8.

17. Tabarsi N, Guan M, Simmonds J, Toma M, Kiess M, Tsang V, et al. Meta-analysis of the effectiveness of heart transplantation in patients with a failing Fontan. Am J Cardiol. 2017;119:1269-74.

18. Simpson KE, Cibulka N, Lee CK, Huddleston CH, Canter CE. Failed Fontan heart transplant candidates with preserved vs impaired ventricular ejection: 2 distinct patient populations. J Heart Lung Transplant. 2012;31:545-7.

19. Miller JR, Simpson KE, Epstein DJ, Lancaster TS, Henn MC, Schuessler RB, et al. Improved survival after heart transplant for failed Fontan patients with preserved ventricular function. J Heart Lung Transplant. 2016;35:877-83.

20. Mitchell MB, Campbell DN, Ivy D, Boucek MM, Sondheimer HM Pietra B, et al. Evidence of pulmonary vascular disease after heart transplantation for Fontan circulation failure. J Thorac Cardiovasc Surg. 2004;128:693-702.

21. Patarroyo M, Simbaqueba C, Shrestha K, Starling RC, Smedira N, Tang WHW et al. Pre-operative risk factors and clinical outcomes associated with vasoplegia in recipients of orthotopic heart transplantation in the contemporary era. $J$ Heart Lung Transplant. 2012;31:282-7.

22. Binotto MA, Maeda NY, Lopes AA. Altered endothelial function following the Fontan procedure. Cardiol Young. 2008;18:70-4.

23. Kirklin JK, Pearce FB, Dabal RJ, Carlo WFJR, Mauchley DC. Challenges of cardiac transplantation following the Fontan procedure. World J Pediatr Congenit Heart Surg. 2017;8:480-6.

Key Words: adult congenital heart disease, Fontan circulation, heart transplantation 